\title{
Obesity and smoking: Are they modulators of cough intravesical peak pressure in stress urinary incontinence?
}

\author{
Paulo Emilio Fuganti, John Michael Gowdy, Nilton Cesar Santiago \\ Hospital de Câncer de Londrina (PEF), Parana, Brazil, Summa Health System (JMG), Ohio, Esta- \\ dos Unidos and Hospital Santa Terezinha de Ibiporã (NCS), Parana, Brazil
}

\begin{abstract}
Purpose: SUI (Stress Urinary Incontinence) results from sudden increases in intravesical peak pressures exceeding urethral resistance leading to involuntary urine loss. Obesity and smoking are well established reversible risk factors for SUI and may alter intravesical peak pressures. BMI, smoking status, and other clinical factors were studied to determine their relationship to CIPP (maximal Intravesical Peak Pressures generated by Cough) in SUI complaining women.

Materials and Methods: Three hundred nineteen women complaining of SUI were evaluated with medical history and urodynamics. Age, parity, comorbidities, previous surgery, BMI and history of smoking were obtained. The maximal intravesical peak pressures generated by cough (CIPP) and cough leak point pressure (CLPP) were acquired. Univariate and multivariate analysis were conducted.

Results: Current smokers and former smokers had similar CIPP (170cmH2O and 170cmH2O; p =0.5, respectively); Those individuals who had never smoked had significantly lower CIPP $(140 \mathrm{cmH} 2 \mathrm{O} ; \mathrm{p}=0.000$ and $\mathrm{p}=0.009$ respectively). BMI was directly related to CIPP $(r=0.41 ; p=0.000)$. Vaginal deliveries $(r=-0.15, p=0.08)$ and diabetes $(r=$ $0.15, p=0.016)$ were also directly related to CIPP on univariate analysis. Only smoking status $(p=0.000)$ and BMI $(p=$ 0.000) were independently significantly related to CIPP on multivariate analysis.

Conclusions: Obesity and smoking showed increased CIPP (maximal Intravesical Peak Pressures generated by Cough). While reduced BMI is related to lower CIPP, smoking cessation does not appear to diminish CIPP. These findings suggest that weight loss may reduce incontinence by CIPP modulation. However, the benefits of smoking cessation without additional lifestyle modification, may have no benefit to improve urinary incontinence.
\end{abstract}

Key words: urinary incontinence; obesity; smoking; risk factors; urodynamics

Int Braz J Urol. 2011; 37: 528-533

\section{INTRODUCTION}

Intravesical peak pressures have been frequently used to evaluate urethral resistance (1). Valsalva or cough leak point pressures is used as threshold value that causes urine loss (2). However, little is known about the maximal intravesical peak pressures that can be generated by cough (CIPP). Acute elevations in intravesical pressure that exceed the level of urethral resistance may cause urine loss. Moreover, if the maximal intra- vesical pressure is lowered below the leak point pressure, incontinence could be attenuated.

Risk factors for incontinence may be CIPP modulators. Obesity is a major health problem worldwide and is also linked to stress urinary incontinence (SUI) (3). Recently, investigators demonstrated that weight reduction alone may reduce more than $50 \%$ of the urinary incontinence episodes a week (4). A high chronic intrabdominal pressure, which may result from obesity, has been suggested as risk factor for urine loss among obese women (5). However, stress maneuvers and 
the resultant peak pressures also play a role in incontinence episodes.

We conducted this study to evaluate CIPP in incontinent women and the clinical factors related to this variable.

\section{MATERIALS AND METHODS}

Three hundred nineteen women complaining of SUI were evaluated. Medical history comprised of the following variables: age, parity, comorbidities, previous surgery and smoking status (cigarettes/day, years of smoking, current smoking, previous smoker) was documented. Weight and height were also obtained to calculate BMI. Patients with previously diagnosed neurological conditions such as dementia, stroke, spinal cord injury or Parkinson disease were excluded. Patients with reduced bladder capacity/compliance were also excluded.

Urodynamics were performed as determined by ICS. Saline solution was infused with a filling rate of $30 \mathrm{~mL} / \mathrm{min}$ with continuous intravesical and rectal pressure monitorization. CIPP was obtained in all patients in the standing position. Upon filling the patients' bladder to $300 \mathrm{~mL}$, all women were then asked to cough as hard as possible. This maneuver was performed twice. The highest intravesical pressure was recorded. Patients who could not cough were excluded. Leak point pressures were also obtained.

Univariate and multivariate analysis were performed by SPSS Statistics 17.0.

\section{RESULTS}

One hundred and one (31.7\%) patients were obese, $85(38.2 \%)$ patients were overweight and $96(30.1 \%)$ had normal BMI. Fifty nine (18.5\%) patients were smokers, $24(7.5 \%)$ patients were former smokers and 236 (74\%) women never smoked. Two hundred and forty $(75.2 \%)$ women had urodynamic stress urinary incontinence and CLPPs ranged from $40 \mathrm{cmH}_{2} \mathrm{O}$ to $190 \mathrm{cmH}_{2} \mathrm{O}$ (median $\left.=120 \mathrm{cmH}_{2} \mathrm{O}\right)$. DO was found in $143(44.8 \%)$ patients. CIPP ranged from $60 \mathrm{cmH}_{2} \mathrm{O}$ to $230 \mathrm{~cm}$ $\mathrm{H} 2 \mathrm{O}$ (median $=140 \mathrm{cmH}_{2} \mathrm{O}$ ). Obese and overweight women had significantly greater LPP when compared to normal-weight women $\left(130 \mathrm{cmH}_{2} \mathrm{O}\right.$ vs. $100 \mathrm{cmH}_{2} \mathrm{O}$, respectively; $\left.\mathrm{p}=0.006\right)$. Never smokers had significantly lower leak point pressures than former and current smokers $\left(110 \mathrm{cmH}_{2} \mathrm{O}\right.$ vs. $140 \mathrm{cmH}_{2} \mathrm{O}$, respectively; $\mathrm{p}=0.01$ ).

On univariate analysis BMI, smoking status and diabetes were directly related to CIPP. CIPP was inversely related to the number of vaginal deliveries (Table-1). Median CIPP was $130 \mathrm{cmH}_{2} \mathrm{O}, 149 \mathrm{~cm}$ $\mathrm{H}^{2} \mathrm{O}$ and $170 \mathrm{cmH}_{2} \mathrm{O}$ among normal, overweight and obese women, respectively $(\mathrm{p}=0.000)$ (Figure-1). Current smokers and former smokers had similar CIPP $\left(170 \mathrm{cmH}_{2} \mathrm{O}\right.$ and $170 \mathrm{cmH}_{2} \mathrm{O} ; \mathrm{p}=0.5$, respectively); both groups showed greater CIPP than those who had never smoked (CIPP $=140 \mathrm{cmH}^{2} \mathrm{O} ; \mathrm{p}=$ 0.000 and $p=0.009$ respectively) (Figure-2). Only smoking status and BMI were directly related to CIPP on multivariate analysis (Table-2).

\section{DISCUSSION}

Obesity and smoking are established modifiable factors risk factors for SUI $(3,6)$ an they must be included in the nonsurgical management for SUI. However, the mechanisms by which they determine the predisposition for SUI are still unknown. These factors were studied evaluating the intravesical peak pressures.

In the United States one third of the population is obese and two thirds are overweight (7). The propensity of obese women for urine loss is probably multifactorial, as is the response of SUI to weight loss $(3,8)$. Obesity may stress the pelvic floor and cause nerve stretching, leading to SUI. Chronic elevated intraabdominal pressures have been identified among obese patients which may facilitate SUI (5). However, this mechanism may not account for the peak pressures that directly cause urine loss. In our study, we assessed the maximal intravesical peak pressures generated by cough. In contrast to baseline intravesical resting pressures in obese patients is about $11 \mathrm{cmH}_{2} \mathrm{O}$ higher than non-obese patients (9), we showed that obese women had CIPP values $45 \mathrm{cmH}_{2} \mathrm{O}$ greater than non-obese women. This difference in CIPP between obese and non-obese patients suggests a possible exacerbation of BMI effects by cough in intravesical peak pressures. We showed that 
Table 1 - Clinical factors related to CIPP on univariate analysis.

\begin{tabular}{|c|c|c|c|c|}
\hline BMI & & $28.1(19-44.1)$ & 0.413 & 0.000 \\
\hline \multicolumn{5}{|l|}{ Smoking } \\
\hline Smoking status & & & & 0.000 \\
\hline Pack years & & $1(0-135)$ & & 0.000 \\
\hline Age & & $51(31-70)$ & -0.107 & 0.056 \\
\hline Pregnancy & & $3(0-8)$ & & \\
\hline Vaginal deliveries & & $1(0-8)$ & -0.192 & 0.025 \\
\hline Cesarean deliveries & & $1(0-6)$ & 0.145 & 0.009 \\
\hline \multicolumn{5}{|l|}{ Comorbidity } \\
\hline Diabetes & $32(10.0)$ & & & 0.009 \\
\hline Hypertension & $84(26.3)$ & & & 0.336 \\
\hline COPD & $6(1.9)$ & & & 0.694 \\
\hline Hypothyroidism & $22(6.9)$ & & & 0.760 \\
\hline Major depression & $12(3.8)$ & & & 0.075 \\
\hline \multicolumn{5}{|l|}{ Previous surgery } \\
\hline Hysterectomy & $53(16.6)$ & & & 0.278 \\
\hline Burch colposuspension & $5(1.6)$ & & & 0.517 \\
\hline anterior colpoplasty & $50(15.7)$ & & & 0.963 \\
\hline pubovaginal sling & $7(2.2)$ & & & 0.494 \\
\hline
\end{tabular}

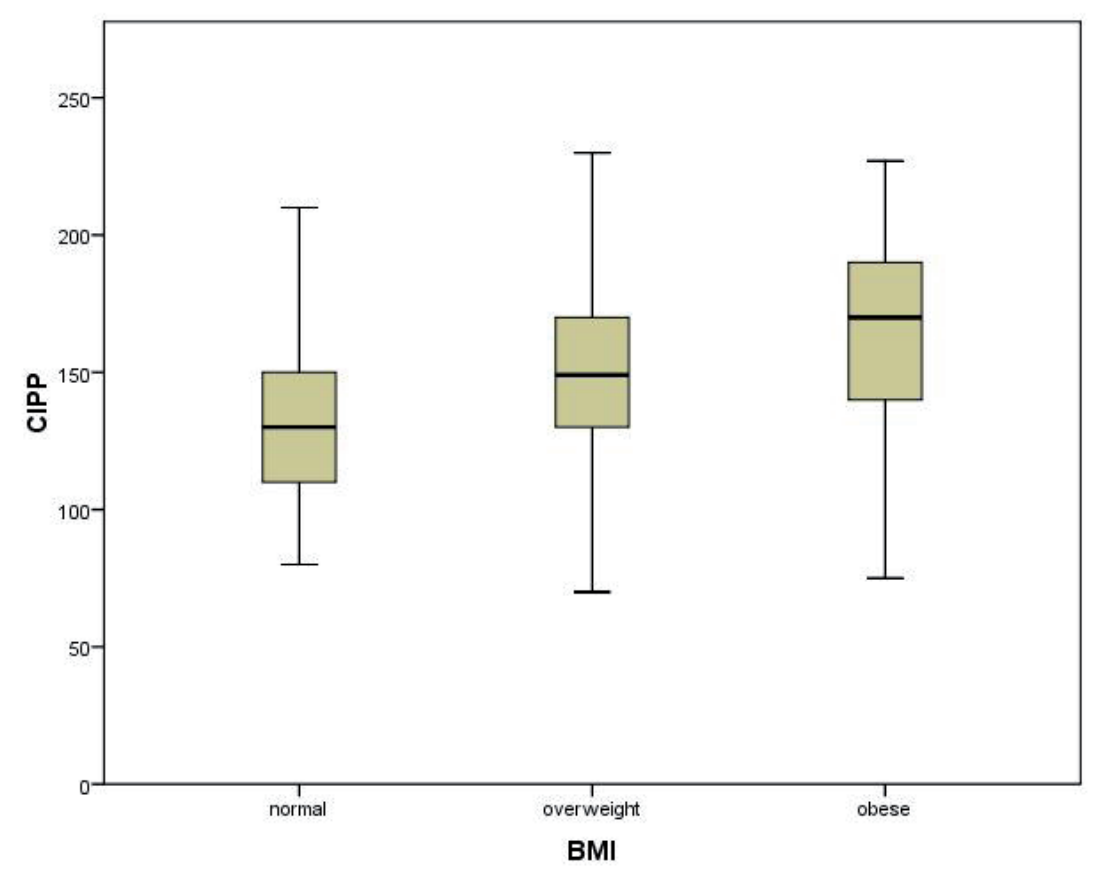

Figure 1 - $\mathrm{CIPP}\left(\mathrm{CmH}_{2} \mathrm{O}\right)$ according to BMI class. 


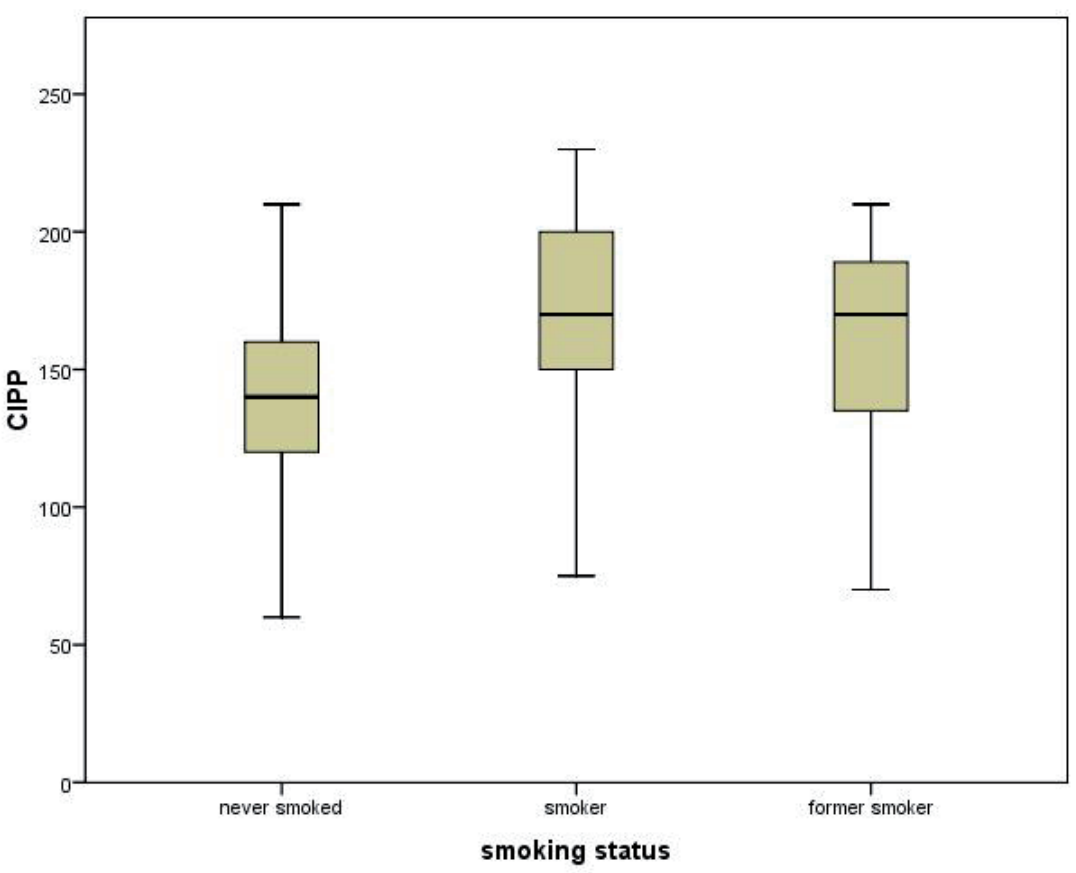

Figure 2 - $\mathrm{CIPP}\left(\mathrm{CmH}_{2} \mathrm{O}\right)$ according to smoking status.

Table 2 - Clinical factors related to CIPP on multivariate analysis.

\begin{tabular}{lcccc}
\hline Clinical factor & $\mathbf{R R}$ & $\mathbf{p}$ & \multicolumn{2}{c}{$\mathbf{9 5 \%}$ Confidence Interval } \\
\hline Diabetes & 4.496 & 0.446 & -7.084 & 16.076 \\
Smoking status & $\mathbf{1 4 . 2 7 0}$ & $\mathbf{0 . 0 0 0}$ & $\mathbf{8 . 8 5 1}$ & $\mathbf{1 9 . 6 8 9}$ \\
BMI & $\mathbf{2 . 6 1 3}$ & $\mathbf{0 . 0 0 0}$ & $\mathbf{1 . 9 3 1}$ & $\mathbf{3 . 2 9 6}$ \\
Vaginal deliveries & -1.418 & 0.076 & -2.986 & 0.151 \\
Cesarean deliveries & 1.372 & 0.408 & -1.887 & 4.631 \\
\hline
\end{tabular}

CIPP increases with BMI and that BMI is also an independent predictor for CIPP. Some studies have already shown the beneficial effects of weight loss on SUI $(4,10,11)$. Nevertheless, one cannot predict the degree of improvement of SUI when treating obesity. We are aware that LPP have questionable utility to predict success after suburethral slings (12). However, in our point of view CIPP should be useful when associated to LPPs among obese incontinent women. Those with higher CIPPs and higher LPPs would be most suited for treatment with strategies that would lower CIPP below LPP, thus improving SUI. Moreover, patients with low LPP and high CIPP may have SUI improvement only with significant weight loss.

Smoking has been found to increase risk for SUI $(6,13)$. We showed higher intravesical peak pressures among smokers. Although these findings have already been suggested (14), this striking difference was not found between current smokers and former smokers. This finding questions the role of smoking status as modifiable risk factor to SUI. Bump et al. (14) studied smoking status and incidence of SUI. Current smokers and former smok- 
ers had similar risks for SUI. These data suggest a long lasting, if not, definitive effect of smoking on pathogenesis of SUI.

The present study focused on intravesical peak pressures and the clinical factors linked to SUI. This approach is obviously simplistic, but revealed that smoking and obesity are independent risk factors for elevated intravesical peak pressures among SUI women. These findings do not diminish the role of all other mechanisms that link obesity and smoking to SUI. However, one should be aware of the potential usefulness of CIPP when treating such risk factors to improve SUI.

\section{CONCLUSIONS}

Obesity and smoking elevated intravesical peak pressures by cough among patients complaining of SUI. Smoking cessation does not reduce cough intravesical peak pressures and may be not a modifiable risk factor for SUI.

\section{CONFLICT OF INTEREST}

None declared.

\section{REFERENCES}

1. Sinha D, Nallaswamy V, Arunkalaivanan AS: Value of leak point pressure study in women with incontinence. J Urol. 2006; 176: 186-8; discussion 188.

2. McGuire EJ: Leak point pressures. In: Cardozo L, Staskin DR, Textbook of Female Urology and Urogynecology. Abingdom, Informa Healthcare, Ch. 19 2006; pp. 265-76.

3. Richter HE, Burgio KL, Brubaker L, Moalli PA, Markland AD, Mallet V, et al.: Factors associated with incontinence frequency in a surgical cohort of stress incontinent women. Am J Obstet Gynecol. 2005; 193: 2088-93.

4. Subak LL, Whitcomb E, Shen H, Saxton J, Vittinghoff E, Brown JS: Weight loss: a novel and effective treatment for urinary incontinence. J Urol. 2005; 174: 190-5.
5. Noblett KL, Jensen JK, Ostergard DR: The relationship of body mass index to intra-abdominal pressure as measured by multichannel cystometry. Int Urogynecol J Pelvic Floor Dysfunct. 1997; 8: 323-6.

6. Hannestad YS, Rortveit G, Daltveit AK, Hunskaar $\mathrm{S}$ : Are smoking and other lifestyle factors associated with female urinary incontinence? The Norwegian EPINCONT Study. BJOG. 2003; 110: 247-54.

7. Flegal KM, Carroll MD, Ogden CL, Curtin LR: Prevalence and trends in obesity among US adults, 1999-2008. JAMA. 2010; 303: 235-41.

8. Danforth KN, Townsend MK, Lifford K, Curhan GC, Resnick NM, Grodstein F: Risk factors for urinary incontinence among middle-aged women. Am J Obstet Gynecol. 2006; 194: 339-45.

9. Sugerman H, Windsor A, Bessos M, Wolfe L: Intraabdominal pressure, sagittal abdominal diameter and obesity comorbidity. J Intern Med. 1997; 241: 71-9.

10. Subak LL, Wing R, West DS, Franklin F, Vittinghoff E, Creasman JM, et al.: Weight loss to treat urinary incontinence in overweight and obese women. N Engl J Med. 2009; 360: 481-90.

11. Auwad W, Steggles P, Bombieri L, Waterfield M, Wilkin T, Freeman R: Moderate weight loss in obese women with urinary incontinence: a prospective longitudinal study. Int Urogynecol J Pelvic Floor Dysfunct. 2008; 19: 1251-9.

12. Costantini E, Lazzeri M, Giannantoni A, Bini V, Vianello A, Kocjancic E, et al.: Preoperative Valsalva leak point pressure may not predict outcome of mid-urethral slings. Analysis from a randomized controlled trial of retropubic versus transobturator mid-urethral slings. Int Braz J Urol. 2008; 34: 7381; discussion 81-3.

13. Bump RC, McClish DK: Cigarette smoking and urinary incontinence in women. Am J Obstet Gynecol. 1992; 167: 1213-8.

14. Bump RC, McClish DM: Cigarette smoking and pure genuine stress incontinence of urine: a comparison of risk factors and determinants between smokers and nonsmokers. Am J Obstet Gynecol. 1994; 170: 579-82.

June 22, 2010

Accepted after revision:

December 03, 2010 


\section{Correspondence address:}

Dr. Paulo Emilio Fuganti

Rua Francisco Marcelino da Silva, 450 - Jardim Itatiaia 2 - Londrina, PR, 86047-160, Brazil

E-mail: paulo100urologia@hotmail.com

\section{EDITORIAL COMMENT}

The recent article, "Obesity and smoking: Are they modulators of cough intravesical peak pressure in stress urinary incontinence?" provides an interesting analysis of the mechanism of SUI in smokers and obese patients.

The findings of an increased maximal intra-vesical pressure and increased cough leak point pressure in this subset of at-risk patients suggest that factors beyond simple urethral hypermobility may be at play. These patients may have a chronic high pressure state, as a possible effect of their underlying medical problems, which predisposes them to stress incontinence and affects their response to surgery. Hence, the use of a sling as a backstop to treat anatomic support defects may not fully address the mechanism of incontinence in these at-risk patients.
Proper attention to co-morbidities through smoking cessation and long term weight loss would be helpful to fully address bothersome incontinence issues. In the management of the adverse health effects of smoking, avoiding irreversible lung disease should be a primary goal of smoking cessation.

In the future, when the population as a whole is aging, yet patients' life expectancy is increasing, the interplay of long term health issues and quality of life concerns such as pelvic floor dysfunction will be increasingly pertinent. Understanding how lifestyle issues can be modified to improve the quality of life in an aging population is not only medically necessary, but will increasingly be a patient driven expectation of our medical profession.

Dr. Kenneth Powers Associate Professor Clinical ObGyn Albert Einstein College of Medicine

Chief of Urogynecology Montefiore M edical Center

Bronx, NY

E-mail:hoppowers@aol.com 